\title{
Case Study: Analysis of Dropout, Repetition and Academic Risk by Higher Education Students at the Universidad Distrital Francisco José de Caldas
}

\author{
Harvey Gómez Castillo ${ }^{1}$, Holman Montiel Ariza ${ }^{2}$ and Miguel Pérez Pereira ${ }^{3}$ \\ Associates Professors, Facultad Tecnológica, Universidad Distrital Francisco José de Caldas, Bogotá D.C, Colombia. \\ ${ }^{1}$ ORCID: 0000-0003-4474-3642, ${ }^{2}$ ORCID: 0000-0002-6077-3510 \\ ${ }^{3}$ ORCID: 0000-0001-7487-2600
}

\begin{abstract}
Globally, some of the aspects that relate to problems in higher education and student academic performance have to do with dropout and repetition of subjects. This article aims to report the research conducted to determine the situation of students in the electronics program of the Universidad Distrital Francisco José de Caldas in Bogotá Colombia; this in order to establish strategies that go beyond those established by the institution to counteract these possible conditions of students.
\end{abstract}

Keywords: Dropout, Academic Risk, Higher Education, Repeating.

\section{INTRODUCTION}

A relevant problem that is common for both developed and developing countries is student dropout [1] [2-5]. This leads to the generation of policies around this phenomenon; because in general, the current university model focuses on education as a service, which focuses on factors such as cost-benefit and of course the possible losses associated with it [6]. However, it must be taken into account that this problem has both social and economic repercussions, affecting both students and society in general [7]; thus forcing to seek mitigation strategies defined as work policies from development plans and ten-year education plans [6].

The study of dropout in higher education students has been developing a wide range of works to identify and adequately characterize the various factors that lead students to this situation [4] [8]. Likewise, there is a growing line of research based on data mining and deep learning techniques, which seek to identify early students at risk, in order to accompany them, prevent failure and reduce the dropout rate affecting higher education institutions [9-14].

The Ministry of Education states that the dropout factor in Colombia is due to the academic dimension "associated with the potential or cultural and academic capital with which students enter higher education," followed by financial and socioeconomic factors, institutional factors, and finally vocational and professional factors [15]. With the implementation of the System for the Prevention and Analysis of Dropout in Higher Education Institutions SPADIES, to perform monitoring functions, calculate the risk, and classify by groups the students of the IES, in order to facilitate the choice and evaluation of strategies that can counteract this phenomenon within the Colombian higher education institutions; the strategies of the institutions to guarantee the permanence of students, which go through university welfare, vocational orientation, student support programs (academic, financial, psychological) and social-occupational orientation strategies, so that students make better decisions when selecting their careers in higher education, in the decade 2006-2016 the dropout rate was reduced from $11.5 \%$ in 2006 to 9.0 in 2016. However, although the dropout rate in technical and technological programs has been reduced to $17.2 \%$, the dropout rate per cohort shows that by 2015 , more than $50 \%$ of the students who entered this type of education dropped out [16]. When speaking of desertion, reference is made to various forms of student withdrawal, for academic reasons, of a voluntary nature, by temporary withdrawal or permanent withdrawal [17]. The decision can be considered as an "individual event of interruption or disassociation from the institutional academic path resulting from one or more processes at the personal, institutional or social level [18]. In this sense, this definition is chosen because all those states of temporary interruption or definitive dissociation of the student are considered in this study. The main objective of this work was focused on the realization of a study about the repetition, desertion, academic risk of the students of the curricular project of Electronic Technology and its three programs, which allows comparing some aspects with the previous semesters, and thus, raising activities leading to improve those indicators.

\section{MATERIALS AND METHODS}

The development of this study was carried out analyzing three academic periods in the programs of Engineering in Telecommunications, Engineering in Control, and Electronic Technology of the Universidad Distrital Francisco José de Caldas, in terms of desertion and repetition, in order to statistically establish the students' behavior during the academic periods between 2018-3 and 2019-3. It is emphasized that the source of information comes from the figures of the semester closure provided by the assistance of the coordination of the electronic program.

\section{RESULTS AND DISCUSSION}

\section{Desertion}

The Universidad Distrital defines permanence as "the space of time in which the status of student is acquired from the registration and/or the renewals of registration, until the obtaining of the degree in a curricular project. Likewise, it establishes the maximum duration of a student's stay "equivalent to (1.5) times the total number of renewals of enrollments provided for in the study plan in which he or she is 
enrolled," and also clarifies that voluntary withdrawal is not counted in calculating the maximum duration of stay [19]. On the contrary, when we speak of desertion, reference is made to various forms of student withdrawal, for academic reasons, of a voluntary nature; by temporary withdrawal or permanent withdrawal [16]. The decision can be considered as an "individual event of interruption or disassociation from the institutional academic path resulting from one or more processes at the personal, institutional or social level [17]. In this sense, this definition is chosen because all those states of temporary interruption or definitive disengagement of the student must be considered in this study.

The desertion analysis is carried out from the available information, in two sources, the first one that reports institutional accreditation, and its consolidated tables, where an analysis of desertion is already carried out chaining the data semester by semester, but it does not offer the states that allow to account for desertion. A second source of information is the direct data provided by the coordination assistance of the Electronic Technology program, at the time of closing each semester, to carry out the group projection for the following semester.

A precision has to do with the origin of the information, since in the District University it is the academic management system "Condor", which characterizes this information from the assignment of letters for each state of the student, configuring 22 states. Of these states, those that give an account of the desertion can be seen in Table 1 .

Table 1. States that allow desertion review

\begin{tabular}{|l|c|}
\hline Canceled semester & $\mathrm{C}$ \\
\hline Voluntary Retreat & $\mathrm{R}$ \\
\hline Dropout & $\mathrm{W}$ \\
\hline Postponed semester & $\mathrm{P}$ \\
\hline No official registration & $\mathrm{M}$ \\
\hline Sanctioned & $\mathrm{S}$ \\
\hline Loses Student Quality & $\mathrm{U}$ \\
\hline Excluded & $\mathrm{X}$ \\
\hline Failed academic test & $\mathrm{Z}$ \\
\hline
\end{tabular}

The general student population for the Electronic Technology curriculum project for the 2019-3 period is 1077 students as follows. Electronic Technology 731, Control Engineering 182, Telecommunications Engineering 164 at the beginning of the semester, see Table 2.

Table 2. 2019-3 students enrolled

\begin{tabular}{|c|c|c|}
\hline \multicolumn{1}{|c|}{ Programs } & Codes & $\mathbf{2 0 1 9 - 3}$ \\
\hline Electronic Technology & 73 & 22 \\
\hline Electronic Technology & 573 & 628 \\
\hline Electronic Technology & 773 & 36 \\
\hline Electronic Technology & 873 & 45 \\
\hline SUBTOTAL & $\mathbf{4}$ & $\mathbf{7 3 1}$ \\
\hline Control Engineer & 83 & 3 \\
\hline
\end{tabular}

\begin{tabular}{|c|c|c|} 
Control Engineer & 283 & 14 \\
\hline Control Engineer & 383 & 165 \\
\hline SUBTOTAL & $\mathbf{3}$ & $\mathbf{1 8 2}$ \\
\hline Telecommunications Engineer & 273 & 12 \\
\hline Telecommunications Engineer & 373 & 152 \\
\hline SUBTOTAL & $\mathbf{2}$ & $\mathbf{1 6 4}$ \\
\hline TOTAL & $\mathbf{9}$ & $\mathbf{1 0 7 7}$ \\
\hline
\end{tabular}

Of the 731 Electronics Technology students at the end of the semester, 587 students are active, 97 students dropped out, 14 students graduated, and 28 completed courses, and only 3 students are on academic probation, see Figure 1.

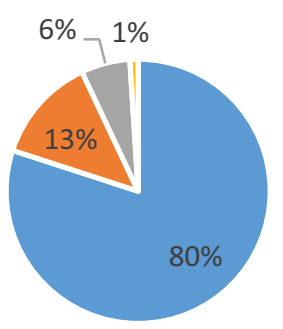

- Active - Desertion - Process completion $=$ Academic risk

Fig. 1. 2019-1 Students electronics technology general situation

With regard to the academic program of Electronic Technology, five states report the dropout of students, where 56 students do not make official the registration (M), 37 dropout (W), 2 cancel the semester $(\mathrm{C})$, one withdraws voluntarily $(\mathrm{R})$, and another one postponed the semester, for a total of 97 students who dropped out for the period 2019-3, of which 60 of them came from academic tests.

In relation to the semester in which students withdraw from the program, 22 are in the first semester; 25 have two semesters of permanence, 18 three semesters, 14 four semesters, 6 students five semesters, and 7 students have more than seven semesters of permanence (codes between 2001-1 and 2014-2), see Figure 2.

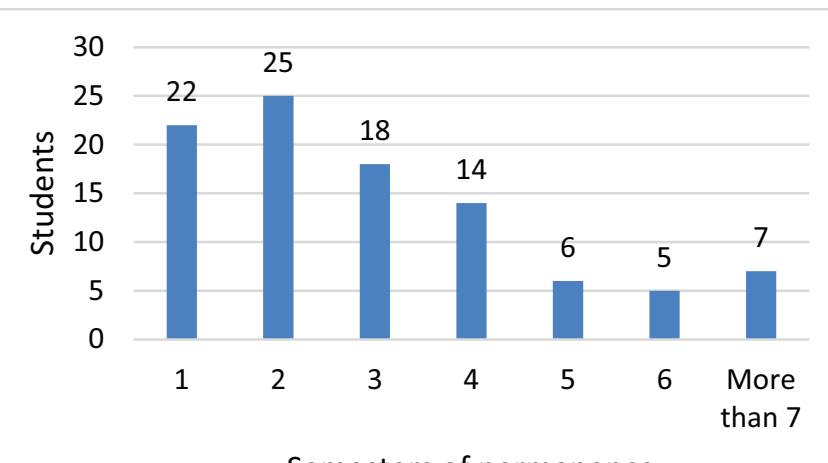

Semesters of permanence

Fig. 2. 2019-3 Electronic Technology - Student Dropout per Semester of permanence 
Comparing the dropout for the most critical program such as the Electronic Technology program from 2018-3 to 2019-3. Comparing the three semesters from 2018-3 to 2019-3 under five states that determine the dropout, it is clear that under normal conditions such as semester 2019-1, the numbers increase significantly, going from 77 students in 2018-3 to 145 students in 2019-1 to 97 students in 2019-3. The dropouts in 2019-1 is manifested with 55 students, is lower in 2019-3 with 37 students, and in 2018-3 with 35 students. It is noticeable how under normal conditions students lose the quality of students (41) cancellations and withdrawals also increase. Something very noticeable is how for 2019-3 56 students do not make official their enrollment data that in the two previous semesters was not reported.

Comparing the two academic periods, dropout indicators soar for the 2019-3 semester, voluntary withdrawals increase from 15 students to 27; dropout-non-renewal of enrollment (W) increases from 33 students to 55, students who lose student status-agreement 004 increases from 0-41, students who pay for the semester and cancel decreases from 29 to 22, see Figure 3.

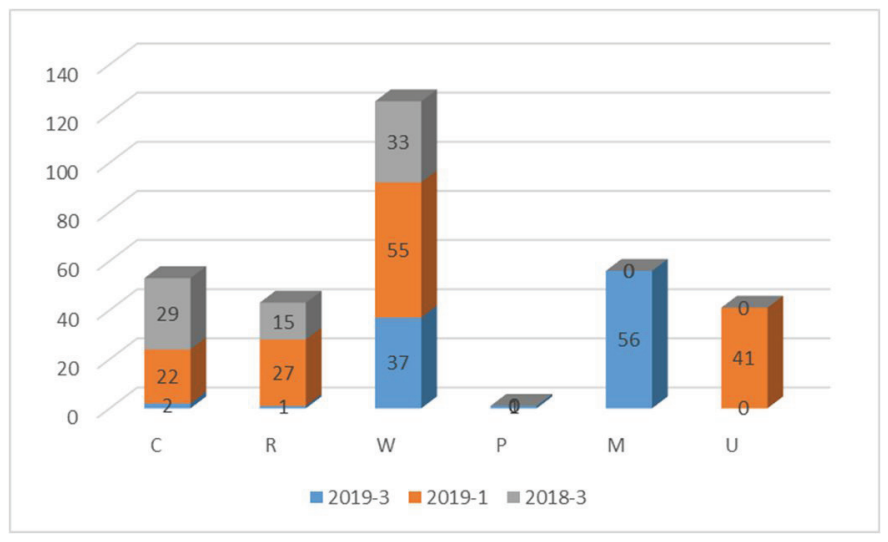

Fig. 3. Comparative student dropout rates 2019-3-20183 Electronic Technology

For the Control Engineering program, 182 students were reported at the end of the 2019-3 semester, of which 150 students are active, 7 students dropped out, 6 students graduated, and 19 completed subjects, with no students on academic probation, see Figure 4.



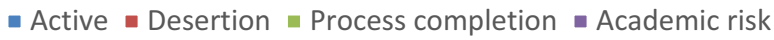

Fig. 4. 2019-3 engineering in control - students general situation
In terms of dropouts, only seven students were reported to have dropped out of nine states that are considered (W). Regarding the semester in which students withdraw from the program, 1 has two semesters of permanence, the remaining 6 students have more than eight (8) semesters of permanence (codes between 2015-1 to 2008-2).

For the Telecommunication Engineering program, 182 students were reported at the end of the 2019-3 semester, of which 150 students are active, 7 students dropped out, 6 students graduated and 19 completed subjects, with no students on academic probation.

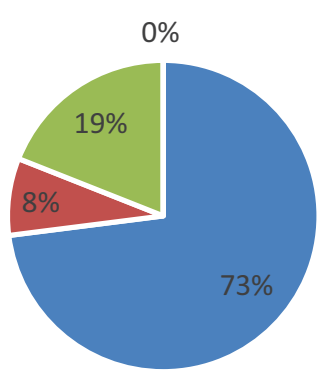

- Active - Desertion - Process completion - Academic risk

Fig. 5. 2019-3 engineering in control - students general situation

As for the desertion of nine states taken into account, data were reported in only four of them, distributed as follows: 10 students dropped out (W), one (1) deferred (P), one more voluntarily withdrew (R), and one did not make official enrollment (M). Of the thirteen (13) students, in relation to the semester in which students withdraw from the program, one (1) has two semesters of permanence, the remaining 12 have more than six (6) semesters of permanence (codes from 2017-1 to 2005-1).

\section{Repetition}

If the repetition rate is understood as the percentage of students who lose an academic space, in relation to the number of students enrolled, the repetition of the electronic technology program for the 2019-3 period concentrates in 12 subjects the highest repetition rate: First there is Linear Algebra, first semester academic space that out of 160 students enrolled 77 lose the subject with a rate of $48.13 \%$; followed by Computer Science and Algorithms, (first semester) with 154 students enrolled, of which 61 lost the subject with a rate of $39.61 \%$; in third place is Differential Calculus, (first semester), which of 168 enrolled 65 lost with a rate of $38.69 \%$; in fourth place is Electromagnetic Fields, which of 13 enrolled lose 5 rate of 38.46\%; fifth place is Electrical Circuits I (second semester) 91 students enrolled lose 29 rate $31.87 \%$; sixth place is Integral Calculus (second semester), which out of 75 students 21 lose with a rate of 28.\%; seventh place is Texts I (first semester) which out of 130 lose 37 students rate $28.46 \%$; eighth place is Physics I (second semester), which out of 92 lose 25 students rate $27.17 \%$; Introduction to electronics (first semester) 123 students enrolled 32 lost rate $26.02 \%$; tenth place is Francisco 
José de Caldas Chair, which out of 123 students lost 29 repetition rate $23.58 \%$; 11 th place is Physics II (third semester), with 16 students who lost the subject out of 66 rate $24.24 \%$; and 12th place is Programming language (second semester) which out of 83 students 20 lost repetition rate $24.10 \%$, see Figure 6.
Comparing the three semesters 2019-3 2019-1 2018-3, it can be determined that within the 21 subjects with the highest rate of repetition are all the subjects from the first semester (Seven 7); six (6) subjects from seven of the second semester; four (4) subjects from five of the third semester; three (3) from the fourth semester and one from the propaedeutic, as can be seen in table 3 .

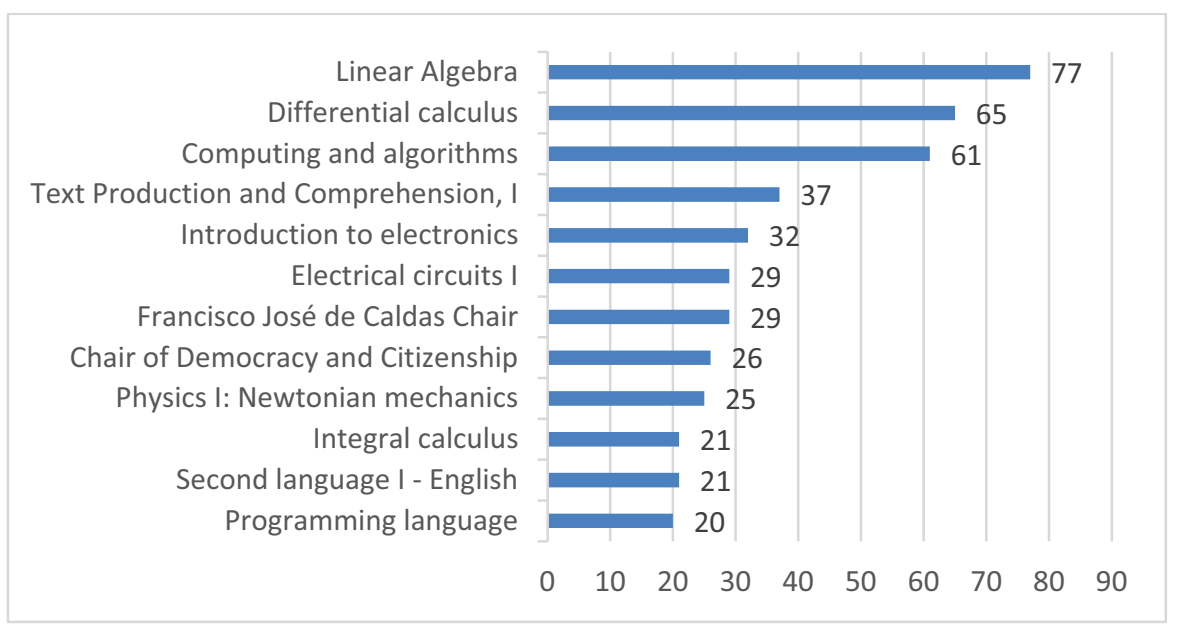

Fig. 6. 2019-3 Subjects with the highest repetition rate in the Electronic Technology program

Table 3. Electronic technology- Subjects with the highest repetition rate 2019-3-2018-3

\begin{tabular}{|c|c|c|c|}
\hline No. & Semester & Academic space & Repetition rate \\
\hline 1 & First & Linear Algebra & $56,98 \%$ \\
\hline 2 & First & Differential calculus & $53,84 \%$ \\
\hline 3 & First & Computing and algorithms & $46,97 \%$ \\
\hline 4 & Second & Physics I: Newtonian mechanics & $40,12 \%$ \\
\hline 5 & Second & Electrical circuits I & $37,99 \%$ \\
\hline 6 & Propaedeutic & Electromagnetic fields & $37,38 \%$ \\
\hline 7 & Third & Physics II: electromagnetism & $34,17 \%$ \\
\hline 8 & Second & Integral calculus & $33,99 \%$ \\
\hline 9 & First & Text Production and Comprehension, I & $31,24 \%$ \\
\hline 10 & Fourth & Electronics II & $30,02 \%$ \\
\hline 11 & First & Introduction to electronics & $29,98 \%$ \\
\hline 12 & First & Francisco José de Caldas Chair & $28,58 \%$ \\
\hline 13 & Second & Text Production and Comprehension II & $25,08 \%$ \\
\hline 14 & Third & Electronics I & $24,18 \%$ \\
\hline 15 & Third & Multivariate calculation & $23,45 \%$ \\
\hline 16 & First & Chair of Democracy and Citizenship & $23,41 \%$ \\
\hline 17 & Fourth & differential equations & $23,30 \%$ \\
\hline 18 & Third & Electrical circuits II & $23,08 \%$ \\
\hline 19 & Second & Programming language & $21,30 \%$ \\
\hline 20 & Fourth & Second language I - English & $21,72 \%$ \\
\hline 21 & Second & Science, technology and society & $20,46 \%$ \\
\hline 22 & Fourth & Physics III: waves and modern physics & $19,18 \%$ \\
\hline
\end{tabular}


For Control Engineering, in the 2019-3 semester the subjects with the highest repetition rate in the program are Control I (10\%), Control III 7\%, Control II (digital) $4 \%$.

Telecommunications Engineering, in the 2019-3 semester four subjects concentrate the repetition of Antennas and Propagation (15\%), Data Mining (18\%), Network Design and Planning (14\%), Mobile Communications (10\%).

\section{Academic Risk}

The Universidad Distrital Francisco José de Caldas, defines in its regulations the academic test in the agreement 027 of 1993 (student statute) [20], in this sense three are the causes of academic test:

a. Not having the cumulative average needed to stay in college.

b. Takes one or more subjects for the third or fourth time, under the terms of the previous article, and

c. Have failed three (3) or more subjects during the same semester

The most common academic test causes in first and second semester students have to do with missing more than three subjects in the same semester, and not having the accumulated average needed to stay in the University, most first semester students are left in two academic tests at the same time. As students have a greater number of renewals, the cumulative average is less likely to be replaced by the third or fourth time that they have passed $70 \%$ of their curriculum (Agreement 027 of 1993) [20]. For this reason, students on academic tests are used as an indicator of academic risk since the loss of the academic test causes them to lose their status as students in the university.

For the 2019-3 academic period, unlike the previous semester (which can be considered a normal semester), there was a surprising decrease in students at academic risk where Electronic Technology reports only three (3) students on academic probation; both Control Engineering and Telecommunications Engineering did not report students on academic probation at the end of the semester or at the beginning of 2020-1.

In the case of engineering programs, in the case of Control Engineering, at the beginning of the semester 11 students were on academic probation, at the end of the semester and beginning of 2020-1, of the 11 seven (7) are active and four (4) dropped out. For Telecommunications, 6 students started on academic probation, of which at the end and beginning of the 2020-1 semester, five (5) were active and one (1) dropped out, see Table 4.
Table 4. 2019-3 2019-1 2018-3 Comparison of Students Testing Electronic Technology Program

\begin{tabular}{|c|c|c|c|}
\hline $\begin{array}{c}\text { Semester } \\
\text { Student } \\
\text { Entrance }\end{array}$ & $\mathbf{2 0 1 9 - 3}$ & $\mathbf{2 0 1 9 - 1}$ & $\mathbf{2 0 1 8 - 3}$ \\
\hline $\mathbf{2 0 1 9 - 3}$ & 3 & 0 & 0 \\
\hline $\mathbf{2 0 1 9 - 1}$ & 0 & 61 & 0 \\
\hline $\mathbf{2 0 1 8 - 2}$ & 0 & 51 & 0 \\
\hline $\mathbf{2 0 1 8 - 1}$ & 0 & 33 & 13 \\
\hline $\mathbf{2 0 1 7 - 2}$ & 0 & 14 & 9 \\
\hline $\mathbf{2 0 1 7 - 1}$ & 0 & 15 & 0 \\
\hline $\mathbf{2 0 1 6 - 2}$ & 0 & 7 & 2 \\
\hline $\mathbf{2 0 1 6 - 1}$ & 0 & 7 & 1 \\
\hline $\mathbf{2 0 1 5 - 2}$ & 0 & 4 & 4 \\
\hline $\mathbf{2 0 1 5 - 1}$ & 0 & 3 & 0 \\
\hline $\mathbf{2 0 1 4 - 2}$ & 0 & 0 & 0 \\
\hline $\mathbf{2 0 1 4 - 1}$ & 0 & 5 & 0 \\
\hline $\mathbf{2 0 1 3 - 2}$ & 0 & 0 & 0 \\
\hline $\mathbf{2 0 1 2 - 2}$ & 0 & 0 & 0 \\
\hline $\mathbf{2 0 1 2 - 1}$ & 0 & 0 & 0 \\
\hline $\mathbf{2 0 0 8 - 1}$ & 0 & 1 & 0 \\
\hline $\mathbf{2 0 0 5 - 1}$ & 0 & & 0 \\
\hline $\mathbf{1 9 9 5 - 2}$ & 0 & 1 & 0 \\
\hline TOTAL & $\mathbf{3}$ & $\mathbf{2 0 2}$ & $\mathbf{2 9}$ \\
\hline
\end{tabular}

\section{CONCLUSIONS}

The findings identified show that, in atypical conditions with strikes, they affect the indicators of dropout repetition, and academic risk in a positive but not real way because it postpones the situation of students for the next semester, as it is manifested in the passage from an atypical semester as 2018 3 to a "normal" 2019-1.

With respect to the repetition of subjects, from the comparison of the three semesters 2019-3 2019-1 2018-3, it is evident that this is concentrated in the first three semesters of Electronic Technology, and as students accumulate semesters completed it tends to decrease.

In the case of students at academic risk, the situation is strange, if you consider that at the beginning of the 2019-3 semester, in the Electronic Technology program 176 students began the semester as active on academic probation (state B), additionally 45 more students were reported under the academic probation and vacation status (state J), which accounts for 221 students on academic probation, so that at the end of the semester only 3 were on probation, and 60 of 97 who withdrew were also on academic probation. 158 students are lost because their status cannot be established with certainty, since due to negotiations by the students with the university's administration for the completion of the 2019-3 semester, it was established that they could not be reported on academic probation for 2020-1, and 
they are listed as active, so the tracking of 2019-3 probationary students is lost.

In order to minimize these factors that affect the academic population in general and due to the identification of the critical situation of repetition by students with the first and second semester courses, the following proposals are made focused on the relief of the situation in mention:

- Create a math foundation course.

- Take an inter-semester reinforcement course, for students, who enroll in the first semester.

- For students at academic risk, accompaniment by the program's professors, to be aware of their process.

- Make use of interns to help in the conceptualization and previous foundation required by the students, this should be clarified by the teachers at the beginning of the course (knowledge prerequisites).

- Support the initial foundation with eggs (virtual learning objects) that can be used by first semester students, but this should be a task supported mainly by the research groups or the math group.

- Monitoring of students, academic testing (characterization), socialization of previous students' results.

- Characterize why students drop out, which ones do it, why this is not the career and choose another area in another field of knowledge, because the career does not meet their expectations / because of the level of demand/ because of the marked orientation towards mathematics.

\section{REFERENCES}

[1] Noboa, C., Ordóñez, M., \& Magallanes, J. Statistical Learning to Detect Potential Dropouts in Higher Education: A Public University Case Study. Learning Analytics for Latin America 2018, 2231, 12-21, 2018.

[2] J. Cody Davidson \& Kristin B. Wilson. Community College Student Dropouts from Higher Education: Toward a Comprehensive Conceptual Model, Community College Journal of Research and Practice, 41:8, 517-530, 2017.

DOI: $10.1080 / 10668926.2016 .1206490$

[3] Zając, T.Z., Komendant-Brodowska, A. Premeditated, dismissed and disenchanted: higher education dropouts in Poland. Tert Educ Manag 25, 1-16, 2019. https://doi.org/10.1007/s11233-018-09010-z

[4] Truta, C.; Parv, L.; Topala, I. Academic Engagement and Intention to Drop Out: Levers for Sustainability in Higher Education. Sustainability, 10, 4637, 2018.

[5] Lucas M. Jeno, Anne G. Danielsen \& Arild Raaheim. A prospective investigation of students' academic achievement and dropout in higher education: a SelfDetermination Theory approach, Educational Psychology, 38:9, 1163- 1184, 2018.

DOI: $10.1080 / 01443410.2018 .1502412$
[6] Guerrero, S. and SOTO, D. La política educativa en torno a la masificación de la educación superior y su relación con el abandono universitario en Colombia. Rev.hist.educ.latinoam., Tunja , v. 21, n. 32, p. 109-136, June 2019. http://dx.doi.org/10.19053/01227238.9201.

[7] Munizaga, F., Cifuentes, M., Beltrán A. Student retention and dropout in Higher Education in Latin America and the Caribbean: A systematic review. education policy analysis archives, [S.1.], v. 26, p. 61, 2018. doi:https://doi.org/10.14507/epaa.26.3348.

[8] Hettiarachchi, A. A., \& Senevirathne, J. M. T. K. The Factors Contributing To Dropouts And Incomplete Academic Standing; A study on Architecture Undergraduates of University of Moratuwa. FARU PROCEEDINGS-2016, 44, 2016.

[9] Sukhbaatar, O., Ogata, K. and Usagawa, T. "Mining Educational Data to Predict Academic Dropouts: a Case Study in Blended Learning Course," TENCON 2018 2018 IEEE Region 10 Conference, Jeju, Korea (South), pp. 2205-2208, 2018. doi: 10.1109/TENCON.2018.8650138.

[10] Hegde, V. and Prageeth, P. Higher education student dropout prediction and analysis through educational data mining. 2018 2nd International Conference on Inventive Systems and Control (ICISC), Coimbatore, pp. 694-699, 2018. doi: 10.1109/ICISC.2018.8398887.

[11] Brezavšček, A., Bach, M., and Baggia, A. Markov Analysis of Students' Performance and Academic Progress in Higher Education. Organizacija 50, 2, 83-95, 2017. https://doi.org/10.1515/orga-2017-0006

[12] Rovira S, Puertas E, Igual L. Data-driven system to predict academic grades and dropout. PLoS ONE 12(2): e0171207, 2017. https://doi.org/10.1371/journal.pone.0171207

[13] Sattar Ameri, Mahtab J. Fard, Ratna B. Chinnam, and Chandan K. Reddy. Survival Analysis based Framework for Early Prediction of Student Dropouts. In Proceedings of the 25th ACM International on Conference on Information and Knowledge Management (CIKM '16). Association for Computing Machinery, New York, NY, USA, 903-912, 2016. https://doi.org/10.1145/2983323.2983351

[14] Nagy, M. and Molontay, R. Predicting Dropout in Higher Education Based on Secondary School Performance. 2018 IEEE 22nd International Conference on Intelligent Engineering Systems (INES), Las Palmas de Gran Canaria, pp. 000389-000394, 2018. doi: 10.1109/INES.2018.8523888. 
[15] Ministerio de Educación Nacional. Deserción estudiantil en la educación superior colombiana. Metodología de seguimiento, diagnóstico y elementos para su prevención. Bogotá, MEN, 2009.

[16] Plan Nacional Decenal de Educación 2016-2026. http://www.plandecenal.edu.co/cms/media/herramientas/ PNDE\%20FINAL_ISBN\%20web.pdf

[17] Rodríguez, M. La investigación sobre deserción universitaria en Colombia 2006-2016. Tendencias y resultados. Pedagogía y Saberes, 51, 49-66, 2019.

[18] Castaño, E. Gallón, S. Gómez, K. \& Vásquez, J. Deserción estudiantil universitaria una aplicación de modelos de duración. Lecturas de Economía, 60, pp. 4165, 2004.

[19] Universidad Distrital Francisco José de Caldas Consejo superior universitario. Acuerdo 004 "por el cual se modifica el acuerdo 003 del 08 de agosto de 2011, 2011.

[20] Universidad Distrital Francisco José de Caldas Consejo superior universitario. Acuerdo 027 "por el cual se expide el estatuto estudiantil de la Universidad Distrital Francisco José de Caldas", 1993. 